\title{
Client satisfaction on community based health insurance scheme and associated factors at Boru Meda Hospital, Northeast, Ethiopia: institutional based cross-sectional study
}

Mulugeta Tasew Hailie ${ }^{1 *}$, Seid Legesse Hassen ${ }^{2}$ and Minwuyelet Maru Temesgen ${ }^{2}$

\begin{abstract}
Background: Community-based health insurance systems are usually voluntary and characterized by community members pooling funds and protecting themselves against the high costs of seeking medical care and treatment for illness. Client satisfaction with health service provision during the implementation of health insurance schemes has often been neglected. This study aimed to determine client satisfaction with the community-based health insurance scheme and associated factors.

Methods: An institutional-based cross-sectional study design was applied from February 22-March 11 /2019. A total of 420 study participants were included in the study using a systematic random sampling technique. Data were collected using a pretested semi-structured interviewer-administered questionnaire with a patient exit interview. Bivariate and multivariate logistic regression analyses were used to identify factors associated with Community-based Health Insurance of client satisfaction. Statistical significance was decided at a $p$-value less than 0.05 .

Result: A total of 420 community-based health insurance clients of health service users participated in the study with a $100 \%$ response rate. The overall client satisfaction was $80 \%$ at $95 \% \mathrm{Cl}(76.1,83.9)$, respondents who have perceived that partially or none availability of prescribing drugs were 0.09 times less likely satisfied as compared to full availability of prescribing drugs (AOR $=0.09 ; 95 \% \mathrm{Cl}:(0.04,0.19)$ ). Besides, study participants waiting time to consult service providers within 30 min were more satisfied than those who were delayed 60 min and above (AOR $=3.16 ; 95 \% \mathrm{Cl}:(1.19,8.41))$.
\end{abstract}

\footnotetext{
* Correspondence: mulugetatasew145@gmail.com

${ }^{1}$ Amhara Public Health Institute, Planning, Monitoring, and Evaluation Directorate, Dessie, Ethiopia

Full list of author information is available at the end of the article
}

(c) The Author(s). 2021 Open Access This article is licensed under a Creative Commons Attribution 4.0 International License, which permits use, sharing, adaptation, distribution and reproduction in any medium or format, as long as you give appropriate credit to the original author(s) and the source, provide a link to the Creative Commons licence, and indicate if changes were made. The images or other third party material in this article are included in the article's Creative Commons licence, unless indicated otherwise in a credit line to the material. If material is not included in the article's Creative Commons licence and your intended use is not permitted by statutory regulation or exceeds the permitted use, you will need to obtain permission directly from the copyright holder. To view a copy of this licence, visit http://creativecommons.org/licenses/by/4.0/ The Creative Commons Public Domain Dedication waiver (http://creativecommons.org/publicdomain/zero/1.0/) applies to the data made available in this article, unless otherwise stated in a credit line to the data. 


\begin{abstract}
Conclusion: Community-based health insurance client satisfaction provided in the present study was $80 \%$ indicating low proportion. Full availability of prescribing drugs, clients renewed their community-based health insurance membership, and preference of clients to use the hospital for future health care need were positively associated with client satisfaction while the perception of waiting time before physician consultation negatively affected client's satisfaction. Therefore, the hospital management members and service providers need to give attention to reduce waiting time preceding consultation, improve drug availability, and sustain the hospital preference by the client.
\end{abstract}

Keywords: Community-based health insurance, Client satisfaction, Hospital Ethiopia

\section{Background}

Community-based health insurance (CBHI) schemes are usually voluntary and characterized by community members pooling funds and to protect themselves against the high costs of seeking medical care and treatment for illness $[1,2]$. Inability to pay the out-of-pocket (OOP) expenditure has been pushed as one of the main impediments to access healthcare particularly for the poor and the vulnerable population [3]. Over the last twenty years, $\mathrm{CBHI}$ has rapidly grown as a health financing tool in low and middle-income countries [4]. It has become one of the key risk-protection schemes and is expected to play a great role in helping the country move towards universal coverage in the health sector $[5,6]$.

However, globally every year around 150 million people suffer from financial devastation and about 100 million are pushed into poverty because of high out-ofpocket payments for health care services. The majority of these people reside in developing countries [7-9]. Health insurance schemes in many low and middleincome countries (LMICs), most especially in the African continent are still in their early stages of implementation with the goal of Universal Coverage [10]. Direct payment for seeking care is considered as regressive as it inhibits access to health services for the poor. It is also considered to contribute to the impoverishment of families due to having to pay for unexpected health care services at the time of illness [11].

Ethiopia has one of the worst health outcomes in the world. OOP payment at the time of seeking health care continues to be one of the major sources of financing for health in Ethiopia [12, 13]. However, in recent years a new health policy results from some improvements in the population's health, and a new health financing strategy led to critical changes in the financing structure of healthcare [14]. The Federal Ministry of Health (FMOH) of Ethiopia developed a mutual health insurance strategy for CBHI schemes. The CBHI targets those employed in the rural and informal sectors [15]. The Government of Ethiopia launched CBHI schemes in 13 pilot woredas in Amhara, Oromia, Southern Nations, Nationalities, and Peoples (SNNP), and Tigray National Regional States in 2010/11 to provide risk protection for those employed in the rural and the informal sectors. The Ethiopian health insurance agency now is working by enhancing risk pooling between the rich and poor as well as between healthy and sick $[16,17]$. The benefits packages of CBHI in Ethiopia include all family health services and curative care that are part of the essential health package which excludes dental implantation and optics services [16]. The client's satisfaction is a multidimensional and broader concept taking into account the individual perceptions, expectations, and experience together $[18,19]$. It is determined by service quality, clients' expectations, subjective disconfirmation, and emotions experienced during service delivery [20-22]. The satisfaction of enrollees and its influencing factors have been providing evidence that has assisted in policy and decision making [23]. Furthermore, client satisfaction studies allow service users' voices to be heard and confirm their experience for improved health care planning [24, 25]. The main reasons cited for dissatisfaction with the quality of care include drug stock out, lengthy waiting time, lack of courtesy on the part of the staff assigned in the facilities, and inadequate availability of diagnostic service [25]. These problems cause a major challenge to CBHI members, greater than to the general community; because members have to pay the out-of-pocket payment for drugs, diagnostic, and other health services in noncontracted health facilities [15]. It leads to additional expenses and causes CBHI scheme members dissatisfied. Therefore, conducting such research on this area is important to determine $\mathrm{CBHI}$ client satisfaction and its associated factors in the hospital setting to alleviate the problem and assured the continuous attractiveness of the care contracted.

In general client satisfaction studies are rarely collected or used as part of designing health insurance schemes in developing countries like Ghana about 76\% [26], in Tamil Nadu, south India 82\% [20], There are fewer studies from the Ethiopian scenario related to CBHI client satisfaction [27, 28], but the level of CBHI client satisfaction in the study area is not studied so far. Therefore, this study aimed to measure the level of institutional-based CBHI clients' satisfaction after a visit to health care services and factors associated with it in 
Boru Meda hospital. So this study provides evidencebased information to improve health service delivery and also, help to fill gaps that ultimately contribute to the desirable quality of Clients' services in the hospital and enhancing the level of clients' satisfaction.

\section{Methods and materials}

\section{Study design, period, and setting}

An institutional-based cross-sectional study was carried out between February 22-March 11/2019, at Boru Meda Hospital, Northeast, Ethiopia. Boru Meda hospital is located $410 \mathrm{~km}$ away from Addis Ababa the capital city of Ethiopia and $10 \mathrm{~km}$ from Dessie city administration in the north direction. It is a primary hospital running an annual budget of Birr more than 20 million with a bed capacity of over 80 and a total staff exceeding 270. It provides services for approximately 1051 inpatients, 964 emergency cases, and 46,651outpatient attendants per year among these 9330 clients were enrolled in CBHI. Since the beginning of the CBHI pilot scheme implementation in Ethiopia, this hospital has been providing services for different woredas for insured clients who had taken contract agreement.

\section{Source population and study population}

The study population included all CBHI members who newly joined and renewed CBHI membership at the time of the study period and those clients who got health care service in the hospital. Clients under 18 years, their parents, or caretakers were interviewed.

\section{Sample size and sampling procedure}

The sample size was calculated using the single population proportion formula with the following assumptions; proportion of client satisfaction $54.4 \%$ from Wolaita Sodo university teaching hospital [29], using a 5\% margin of error at $95 \%$ confidence level. The final sample size was 420 after considering 10\% non-response rate. The total sample size was proportionately allocated for each service delivery unit in the hospital depending on the average number of clients who visited the service area one month before the start of the study. Then study participants were identified by systematic random sampling and coded with the help of triage order at the patient entry point. In addition, Simple random sampling was done for the first clients to get the starting point. Thereafter, depending on sampling interval clients' coming to the service delivery exit were enrolled in the study until the required sample size was obtained.

\section{Data collection procedures}

Data were collected using pre-tested structured questionnaires by exit interview in four confidential rooms. The questionnaire was adapted from the Ethiopia health insurance agency evaluation report 2015 [15] with a slight modification made with the objective of this particular study and to fit with the local context. The questionnaire, which was initially prepared in English and translated into the local language, Amharic, by those proficient in the language, and checked for consistency. Five percent of the questionnaires were pre-tested before the actual data collection period in a comparable setting. Finally, the interview was administered by six health care providers who have BSc nurse for data collection, and one health officer for supervision activities was recruited. Supervisors and principal investigators oversaw the data collection daily.

\section{Data processing and analysis}

The collected data were checked for completeness and consistency, then coded, and entered into Epi Info 7.1, and exported to SPSS version 21 statistical software for final analysis. Principal Component Analysis with varimax rotation was used to compute the wealth index of the client. Categorical variables used measure income were transformed into separate dichotomous (0-1) indicators. These indicators and those that are continuous are then examined using a principal components analysis to produce a common factor score for each client's household. The resulting combined wealth index has a mean of zero and a standard deviation of one. Once the index is computed, ranking each person in the population by his or her score, and then dividing the ranking into three equal categories (poor, medium, and rich), each comprising $33.3 \%$ of the client. Simple descriptive analyses were used to describe the study population correlated to relevant variables and presented using text, table, frequency, and percentage. Variables that have a $p$-value $\leq$ of 0.2 on bivariate analyses were entered in the multivariate logistic regression model to identify independent variables of enrollment into CBHI. $P<0.05$ was considered statistically significant. The strength of association and precision were examined using an adjusted odds ratio at a $95 \%$ confidence interval. The model fitness was checked by Hosmer and Lemeshow's goodness of fit test.

\section{Operational definition}

Clients need to receive medical care for their illness and/or caregivers for children, elders, and seriously ill families.

\section{Level of client's satisfaction}

Five measuring items were used in the scale to measure satisfaction together yield a maximum score of 25 and a minimum score of 5. Satisfaction level was measured by the responses for every five items was summed and transformed to give an individual level satisfaction score 
from 0 to $100 \%$ for each item used as a percentage mean score.

\section{Overall satisfaction level}

Seventy five percent and above response rate of the five satisfaction measuring items were categorized as "satisfied" and those who were satisfied in less than $75 \%$ of the five satisfaction measuring items were categorized as "Dissatisfied" [29].

\section{Wealth index}

The index was constructed using clients' household asset data via a principal components analysis. Once the index is computed, ranking each person in the population by his or her score, and then dividing the ranking into three equal categories, each comprising $33.3 \%$ of the clients [30] those whose score $<33.3$ were categorized as poor, those score between 33.3 and 66.6 were categorized as medium and those score $>66.6$ were categorized as rich.

\section{Results}

Socio-demographic characteristic of the respondent

A total of $420 \mathrm{CBHI}$ members of health service users participated in the study with a $100 \%$ response rate. Of the total participants, 228 (54\%) were male and 268 $(63.8 \%)$ were married. The median age of respondents was 40 years with an Interquartile range of 33 (22-55) years (Table 1).

\section{Institutional aspect and pattern of clients Visit}

Among the total number of hospital visited CBHI clients 120 (28.1\%) were due to fever followed by 97 (23.1\%) dermatology cases. More than 177 (42.1\%) of clients were waiting for 30-60 min to consult a physician. Out of 247 Clients who were sent to laboratory diagnosis 151 (61.4\%) completed within 30-60 min. More than $76 \%$ of clients came far from $10 \mathrm{~km}$ and only $34.3 \%$ of clients have transport access.

\section{Client satisfaction and quality of service}

This exit interview assessed the satisfaction of CBHI member clients during service delivery. Among the outpatient clients the cleanliness of the hospital was highest satisfaction rate 387 (98.7\%) and satisfaction was rated lowest $299(71.2 \%)$ with the availability of drugs. Out of 28 admitted Clients who participated in study $21(75 \%)$ of them were satisfied by the attentiveness and adequate follow-up of nursing staff. Out of 420 clients, 247 (58\%) were ordered to laboratory diagnosis. Thirty-one (7.3\%) clients had got radiology service. All clients got prescription paper for drugs and Supplies, but only $73.1 \%$ of them were getting all the prescribed drugs and 119 (28.3\%) were dissatisfied concerning with the availability of drugs in the hospital (Table 2).
Table 1 Socio-Demographic characteristics of Respondents with health care services provided at Boru Meda hospital, Feb.22Mar.11/ 2019 ( $n=420)$

\begin{tabular}{|c|c|c|}
\hline Variable & Number & Percent \\
\hline \multicolumn{3}{|l|}{ Age category (in year) } \\
\hline$<=18$ & 87 & 20.7 \\
\hline $19-29$ & 48 & 11.4 \\
\hline $30-39$ & 69 & 16.4 \\
\hline $40-49$ & 62 & 14.8 \\
\hline $50-59$ & 72 & 17.1 \\
\hline$>=60$ & 82 & 19.5 \\
\hline \multicolumn{3}{|l|}{ Sex } \\
\hline Male & 228 & 54.3 \\
\hline Female & 192 & 45.7 \\
\hline \multicolumn{3}{|l|}{ Educational status } \\
\hline Unable to read and write & 230 & 54.8 \\
\hline Able to read and write & 28 & 6.7 \\
\hline $1-8$ & 115 & 27.4 \\
\hline $9-12$ & 45 & 10.7 \\
\hline TVET/Collage/University) & 2 & 0.5 \\
\hline \multicolumn{3}{|l|}{ Religion } \\
\hline Orthodox & 113 & 26.9 \\
\hline Muslim & 307 & 73.1 \\
\hline \multicolumn{3}{|l|}{ Marital status } \\
\hline Married & 268 & 68.8 \\
\hline Single & 119 & 28.3 \\
\hline Widowed & 19 & 4.5 \\
\hline divorced & 14 & 3.3 \\
\hline \multicolumn{3}{|l|}{ Occupation } \\
\hline Farmer & 299 & 71.2 \\
\hline Unemployed & 23 & 5.5 \\
\hline Student & 72 & 17.1 \\
\hline Merchant & 8 & 1.9 \\
\hline Others & 18 & 4.3 \\
\hline \multicolumn{3}{|l|}{ Ethnics } \\
\hline Amhara & 418 & 99.5 \\
\hline Oromo & 2 & 0.5 \\
\hline \multicolumn{3}{|c|}{ Fee waiver beneficiary before $\mathrm{CBHI}$} \\
\hline Yes & 36 & 8.6 \\
\hline No & 384 & 91.4 \\
\hline \multicolumn{3}{|l|}{ Wealth index } \\
\hline Poor & 140 & 33.3 \\
\hline Medium & 141 & 33.6 \\
\hline Rich & 139 & 33.1 \\
\hline
\end{tabular}


Table 2 Level of client's satisfaction with different components of health care services at Boru Meda hospital, Feb.22-Mar 11/ 2019 $(n=420)$

\begin{tabular}{|c|c|c|c|c|c|}
\hline Characteristics & v.sat (\%) & Sati (\%) & Neut (\%) & Dissat (\%) & v.disat (\%) \\
\hline Overall quality of service & $138(32.9)$ & $203(48.3)$ & $41(9.8)$ & $28(6.7)$ & $10(2.4)$ \\
\hline Availability of drugs & $101(24)$ & $200(47.6)$ & $33(7.9)$ & $71(16.9)$ & $15(3.6)$ \\
\hline Availability of diagnostic facility $(n=247)$ & $78(31.6)$ & $143(57.9)$ & $9(3.6)$ & $16(6.5)$ & $1(0.4)$ \\
\hline Cleanliness of facility & $244(58.1)$ & $169(40.2)$ & $2(0.5)$ & $3(0.7)$ & $2(0.5)$ \\
\hline Short wait time until seen by physician & $109(26)$ & $229(54.5)$ & $29(6.9)$ & $44(10.5)$ & $9(2.1)$ \\
\hline Short waiting time between services (lab. x-ray...) & $78(31.6)$ & $143(57.9)$ & $9(3.6)$ & $16(6.5)$ & $1(0.4)$ \\
\hline Friendliness of staff & $191(45.5)$ & $204(48.6)$ & $14(3.3)$ & $8(1.9)$ & $3(0.7)$ \\
\hline Attentiveness by the nursing staff (inpatient only $n=28$ ) & $9(32.1)$ & $12(42.9)$ & $4(14.3)$ & $2(7.1)$ & $1(3.6)$ \\
\hline Quality of food and other inpatient facilities $(n=28)$ & 8 (28.6) & $13(46.4)$ & $4(14.3)$ & $3(10.7)$ & 0 \\
\hline
\end{tabular}

\section{Benefit and premium package of $\mathrm{CBHI}$ Scheme}

Concerning the benefits package of the CBHI scheme, out of 420 clients, 280 (66.7\%) of them were a very adequate benefit. Three hundred twenty-six (77.6\%) clients perceived that the premium paid to the scheme is affordable. Two hundred ninety (69\%) of clients were joined the CBHI scheme due of premium was low compared to out-of-pocket payment (OPP) while 218 $(51.9 \%)$ were due to illness or injury that occurred frequently in their families (Table 3).

\section{Determining client satisfaction}

The proportion of respondents who were satisfied with the health care service provided in this study was $80 \%$ at 95\% CI (76.1-83.9\%) computed from satisfaction measuring items.

\section{Factors associated with $\mathrm{CBHI}$ client satisfaction}

In the first bivariate regression model; age $(\mathrm{COR}=2.39$; 95\% Cl: $(1.02-5.59))(p=0.11)$,occupation, $(\mathrm{COR}=2.63$; 95\% Cl: $(1.11-6.25))(p=0.16)$, marital status, $(\mathrm{COR}=$ $0.54 ; 95 \% \mathrm{Cl}:(0.32-0.90))(p=0.18)$ availability of drugs,
$(\mathrm{COR}=0.12 ; 95 \% \mathrm{Cl}:(0.07-.20))(p=0.03)$, waiting time to visit service provider in minutes, $(\mathrm{COR}=4.95 ; 95 \% \mathrm{Cl}$ : $(2.38-10.28))(p=0.04)$ plan to renew CBHI membership, $(\mathrm{COR}=6.27$; 95\% Cl: $(2.97-13.23))(p=0.07)$, Prefer hospital for future health care, $(\mathrm{COR}=14.68 ; 95 \% \mathrm{Cl}$ : $(8.30-25.95))(p=0.08)$ and affordability of the scheme $(\mathrm{COR}=0.13$; $95 \% \mathrm{Cl}:(0.06-0.29))(p=0.14)$, were identified as factors associated with overall CBHI client's satisfaction with $p$-value less than 20 included in multivariable logistic regressions.

In multivariable logistic regression, age, marital status, occupation and other significant variables in bi-variable logistic regression did not contribute to be independent predictors much for $\mathrm{CBHI}$ client satisfaction at ( $p$-value $<0.05)$. However, availability of drugs and supply, waiting time to consult service provider within $30 \mathrm{~min}$ preceding consultation, prefer to the hospital for future health care need and plan to renew CBHI membership of the respondents were significantly associated with CBHI client's satisfaction at $(p<0.05)$ and 95\% Cl. Specifically, being the odds of availability of drugs none or partial, client's satisfaction decline by $91 \%$ compared to

Table 3 Clients viewed about benefit and premium package of CBHI scheme implementation at Boru Meda hospital Feb.22-Mar 11/ $2019(n=420)$

\begin{tabular}{|c|c|c|c|}
\hline Variable & & Frequency & Percent \\
\hline \multirow[t]{4}{*}{ CBHI benefit package } & Very adequate & 280 & 66.7 \\
\hline & Somewhat adequate & 77 & 18.3 \\
\hline & Inadequate & 60 & 14.3 \\
\hline & I don't know & 3 & 0.7 \\
\hline Premium & Affordable & 326 & 77.6 \\
\hline \multirow[t]{2}{*}{ affordability } & Somewhat affordable & 63 & 15 \\
\hline & Not affordable & 31 & 7.4 \\
\hline \multirow[t]{2}{*}{ Plan to renew membership } & Yes & 388 & 92.4 \\
\hline & No & 32 & 7.6 \\
\hline \multirow[t]{2}{*}{ Preference of hospital for future health care } & Yes & 337 & 80.2 \\
\hline & No & 83 & 19.8 \\
\hline
\end{tabular}


full drugs available clients (AOR $=0.09 ; 95 \% \mathrm{Cl}$ : $(0.04$, $0.19)$ ). Clients who had got service within $30 \mathrm{~min}$ were 3.16 times more likely satisfied than clients delayed for more than $60 \mathrm{~min}(\mathrm{AOR}=3.16$; $95 \% \mathrm{Cl}$ : $(1.19,8.41))$. Clients who had the plan to renew their $\mathrm{CBHI}$ membership were 4.96 times more likely satisfied compared to clients who did not plan to renew their CBHI membership $(\mathrm{AOR}=4.96 ; 95 \% \mathrm{Cl}$ : $(1.64,15.02))$. In addition, clients who preferred the hospital for future health care were 10.92 times more likely to be satisfied than clients who did not prefer the hospital for future health care (AOR = 10.92; 95\% Cl: (5.31, 22.45)) (Table 4).

\section{Discussion}

According to the present study, clients who had got physician consultation within thirty minutes were 3.16

Table 4 Bivaiate and multivariate analysis showing factors associated with CBHI client satisfaction at Boru Meda hospital, northeast, Ethiopia; Feb.22-Mar.11/2019 ( $N=420)$

\begin{tabular}{|c|c|c|c|c|}
\hline \multirow[t]{2}{*}{ Explanatory variable } & \multicolumn{2}{|c|}{ Client satisfaction } & \multirow[t]{2}{*}{$\operatorname{COR}(95 \%) \mathrm{Cl}$} & \multirow[t]{2}{*}{$\operatorname{AOR}(95 \%) \mathrm{Cl}$} \\
\hline & Satisfied N (\%) & Dissatisfied N (\%) & & \\
\hline \multicolumn{5}{|l|}{ Age (in years) } \\
\hline$<=18$ & $64(73.6)$ & $23(26.4)$ & 1 & 1 \\
\hline $19-29$ & $31(64.6)$ & $17(35.4)$ & $0.65(0.30-1.40)$ & $0.72(0.25-2.08)$ \\
\hline 30_39 & $60(87)$ & $9(13)$ & $2.39(1.02-5.59)^{*}$ & $3.34(1.00-10.36)$ \\
\hline 40_49 & $53(85.5)$ & $9(14.5)$ & $2.11(0.9-4.96)$ & $1.94(0.59-6.41)$ \\
\hline 50_59 & $60(83.3)$ & $12(16.7)$ & $1.79(0.82-3.92$ & $2.86(0.96-8.50)$ \\
\hline$>=60$ & $68(82.9)$ & $14(17.1)$ & $1.74(0.82-3.68)$ & $1.51(0.57-4.0)$ \\
\hline \multicolumn{5}{|l|}{ Availability of drugs } \\
\hline Fully & $277(90.2)$ & $30(9.8)$ & 1 & 1 \\
\hline Partially\& none & $59(52.2)$ & $54(47.8)$ & $0.12(0.07-.20)^{* * *}$ & $0.09(0.04-0.19)^{* * *}$ \\
\hline \multicolumn{5}{|c|}{ Waiting time to visit service provider in (minutes) } \\
\hline$<30$ & $162(91.5)$ & $15(8.5)$ & $4.95(2.38-10.28)^{* * *}$ & $3.16(1.19-8.41)^{*}$ \\
\hline $31-60$ & $126(72.8)$ & $47(27.2)$ & $1.22(0.67-2.25)$ & $0.83(0.38-1.95)$ \\
\hline$>60$ & $48(68.6)$ & $22(31.4)$ & 1 & 1 \\
\hline \multicolumn{5}{|c|}{ Prefer hospital for future health care } \\
\hline Yes & $304(90.2)$ & $33(9.8)$ & $14.68(8.30-25.95)^{* * *}$ & $10.92(5.31-22.45)^{* * *}$ \\
\hline No & $32(38.6)$ & $51(61.4)$ & 1 & 1 \\
\hline \multicolumn{5}{|l|}{ Occupation } \\
\hline Farmer & $249(83.3)$ & $50(16.7)$ & 1 & 1 \\
\hline Unemployed & $14(60.9)$ & $9(39.1)$ & $2.63(1.11-6.25)^{*}$ & $0.99(0.18-5.36)$ \\
\hline Student & $56(77.8)$ & $16(22.2)$ & $0.82(0.257-0.263)$ & $0.83(0.17-3.97)$ \\
\hline merchant & $17(65.4)$ & $9(34.6)$ & $1.85(0.69-4.94)$ & $0.43(0.09-2.04)$ \\
\hline \multicolumn{5}{|c|}{ Plan to renew $\mathrm{CBH}$ membership } \\
\hline Yes & $322(83)$ & $66(17)$ & $6.27(2.97-13.23)^{* * *}$ & $4.96(1.64-15.02)^{* *}$ \\
\hline No & $14(43.8$ & $18(56.2)$ & 1 & 1 \\
\hline \multicolumn{5}{|l|}{ Affordability of the scheme } \\
\hline Affordable & $274(84.4)$ & $51(15.6)$ & 1 & 1 \\
\hline Somewhat affordable & $48(76.2)$ & $15(23.2)$ & $0.59(0.30-1.13)$ & $0.59(0.30-1.13)$ \\
\hline Not affordable & $13(41.9)$ & $18(58.1)$ & $0.13(0.06-0.29)^{*}$ & $0.64(0.20-2.01)$ \\
\hline \multicolumn{5}{|l|}{ Marital status } \\
\hline Married & $222(82.8)$ & $46(17.2)$ & 1 & 1 \\
\hline Single & $86(72.3)$ & $33(27.7)$ & $0.54(0.32-0.90)^{*}$ & $0.94(0.21-4.1)$ \\
\hline Divorced & $12(85.7)$ & $2(14.3)$ & $1.10(0.30-3.9)$ & $3.77(0.63-22.6)$ \\
\hline Widowed & $16(84.2)$ & $3(14.8)$ & 1. $20(0.26-5.74)$ & $1.34(0.15-11.4)$ \\
\hline
\end{tabular}

(*) $P$-value $<0.05,(* *) P$-value $<0.01(* *), P$ - value $<0.001$. AOR Adjusted odd ratio, COR Crude odd ratio 
times more likely satisfied than clients who had delayed more than sixty minutes. This study supported the studies were conducted in the Nouna district of Burkina Faso, Tamil Nadu of South India, and Wolaita Sodo university teaching hospital $[29,31]$. Therefore, long waiting time before physician consultation negatively affects client satisfaction.

In this finding, $92 \%$ of clients were having a plan to renew their CBHI membership which was higher than studies conducted in the Volta Region of Ghana 76\%, and in Ethiopia 82\% [32, 33]. The difference in the case of Ethiopia might be the variation in design and setup of a study while in Ghana might be sociocultural and longtime experience in the scheme and health service provision. Clients with positive evaluation for the scheme and service provision influence their satisfaction [34, 35].

Being clients preferred to the hospital for future health care 10.92 times more likely satisfied than those who didn't prefer the hospital for future health care needs. It might be due to clients was coming from health centers by referral so that relatively qualified health professionals and better diagnostic instruments were available in the hospital contributed their role. In addition, the perception of clients for the friendliness of staff and cleanliness of the hospital might have played a great role in the preference. This Study supported by a study conducted in the Nadowli District of Ghana indicated that health provider attitude and facility sanitation [36] positively influence client satisfaction.

\section{Limitation}

Clients may stay relatively in a short time whereby they feel more satisfied immediately after their consultation than they do afterward. The use of quantitative techniques to explore perceptions might not have captured critical in-depth responses.

\section{Conclusion and recommendation}

In general, the overall $\mathrm{CBHI}$ client satisfaction provided at Boru Meda hospital was low compared to the national CBHI evaluation. Full availability of prescribing drugs, clients renewed their $\mathrm{CBHI}$ membership, and preference of clients to use the hospital for future health care need positively associated with $\mathrm{CBHI}$ client satisfaction while the perception of waiting time before physician consultation negatively affected client's satisfaction. Therefore, the hospital management members and service providers need to give attention to reduce waiting time preceding consultation, improve drug availability, and sustain the hospital preference by the hospital management members and service providers need to give attention to reduce waiting time preceding consultation, improve drug availability, and sustain the hospital preference by the client. Ministry of Health was also better to design and strengthen strategies sufficient quantity of essential drugs available in the public hospital, and improving public awareness regarding the concept of insurance. CBHI Agency should also follow and monitor the renewal period of CBHI members as per standard create a strategy to reimbursement for clients who did not get service in a contracted health institution. Further study will be proposed supporting with a qualitative study to determine satisfaction of CBHI scheme and health service provision in the study area and the region at large.

\section{Abbreviations}

APHI: Amhara Public Health Institute; CBHI: Community-based Health Insurance; FMOH: Federal Ministry of Health; OOP: out-of-pocket; SHI: social health insurance

\section{Acknowledgments}

We acknowledge Amhara Public Health Institute Dessie Branch for giving us the chance to do this study and covering data enumeration expenses. We also appreciate the administrative staff of Boru Meda Hospital for their cooperation and commitment to this work.

\section{Authors' contributions}

MT has conceived the study, carried out the overall design, analyzed, interpreted the data. Drafted the manuscript, and revised it critically for important intellectual content. SL and MM have revised the design of the study, data collection techniques and helped in statistical analysis. Assisted with the development of the questionnaire and has drafted the manuscript. All authors read and approved the final manuscript.

\section{Funding}

Funding was not received from any organization, but APHI has covered data enumeration costs.

\section{Availability of data and materials}

All the datasets during and/or analyzed during the current study are available from the corresponding author on reasonable request.

\section{Declarations}

Ethics approval and consent to participate

We got Ethical approval from the Institutional Review Committee of Amhara Public Health Institute (Protocol No: APHI-DB/R/T/T/010/13) and a support letter from Dessie city and Boru Meda Hospital administration to get the permission and cooperation of concerned bodies. We got an informed written consent and/assent from each participant and parents or caretakers of the clients below 18 years, which was approved by the ethical review committee of Amhara Public Health Institute. The interviewers took precautionary measures following a brief discussion and explanation of $\mathrm{CBH}$ clients before the interview. The study was conducted under the Declaration of Helsinki.

\section{Consent for publication}

Not Applicable.

\section{Competing interests}

We declare no competing interests.

\section{Author details}

${ }^{1}$ Amhara Public Health Institute, Planning, Monitoring, and Evaluation Directorate, Dessie, Ethiopia. ${ }^{2}$ Amhara Public Health Institute, Research and Technology Transfer Directorate, Dessie, Ethiopia. 
Received: 31 May 2021 Accepted: 25 October 2021

Published online: 30 November 2021

\section{References}

1. Uzochukwu B, Onwujekwe O, Eze S, Ezuma N, Obikeze E, Onoka C. Community Based Health Insurance Scheme in Anambra State, Nigeria: an analysis of policy development, implementation and equity effects. London: Consortium for Research on Equitable Health Systems, London School of Hygiene and Tropical Medicine; 2009. p .1-35.

2. Kebede A, Gebreslassie M, Yitayal M. Willingness to pay for community based health insurance among households in the rural community of Fogera District, North West Ethiopia. Int J Econ Finance Manag Sci. 2014; 2(4):263-9. https://doi.org/10.11648/j.ijefm.20140204.15.

3. Mwaura JW, Pongpanich S. Access to health care: the role of a community based health insurance in Kenya. Pan African Med J. 2012;12(1).

4. Parmar D, Souares A, De Allegri M, Savadogo G, Sauerborn R. Adverse selection in a community-based health insurance scheme in rural Africa: implications for introducing targeted subsidies. BMC Health Serv Res. 2012 12(1):1-8. https://doi.org/10.1186/1472-6963-12-181.

5. Alkenbrack S, Lindelow M. The impact of community-based health insurance on utilization and out-of-pocket expenditures in Lao People's Democratic Republic. Health Econ. 2015;24(4):379-99. https://doi.org/10.1 002/hec.3023.

6. Stoermer M, Fuerst F, Rijal K, Bhandari R, Nogier C, Gautam GS, et al. Review of community-based health insurance initiatives in Nepal. Deutsche Gesellschaft fur internationale Zusammenarbeit (GIZ) Gmbh. 2012

7. Wanyenze RK, Nawavvu C, Namale AS, Mayanja B, Bunnell R, Abang B, et al. Acceptability of routine HIV counselling and testing, and HIV seroprevalence in Ugandan hospitals. Bull World Health Organ. 2008;86(4):302-9. https://doi. org/10.2471/BLT.07.042580.

8. Organization WH. Designing health financing systems to reduce catastrophic health expenditure. Geneva: World Health Organization; 2005.

9. Shahrawat R, Rao KD. Insured yet vulnerable: out-of-pocket payments and India's poor. Health Policy Plan. 2012;27(3):213-21. https://doi.org/10.1093/ heapol/czr029.

10. Ugwu E, Akinboye D, Akinoye J. Predictors of Enrolment in Health Insurance: A Study among Self-employed Workers in ljebu-ode Local Government Area, Ogun State, Nigeria. Prevalence. 352:16. https://doi.org/1 0.21522/TIJPH.2013.08.03.Art001.

11. World Health Organization and University of Queensland. School of Population Health, 2010. Improving the quality and use of birth, death and cause-of-death information: guidance for a standards-based review of country practices.

12. Bobo FT, Yesuf EA, Woldie M. Inequities in utilization of reproductive and maternal health services in Ethiopia. Int J Equity Health. 2017;16(1):1-8 https://doi.org/10.1186/s12939-017-0602-2.

13. Ali EE. Health care financing in Ethiopia: implications on access to essential medicines. Value in health regional issues. 2014;4:37-40. https://doi.org/10.1 016/j.vhri.2014.06.005.

14. Barnett I, Tefera B. Poor Households' Experiences and Perception of User Fees for Healthcare: a mixed-method study from Ethiopia. Young Lives; 2010.

15. Agency EHI. Evaluation of community-based health insurance pilot schemes in Ethiopia. 2015.

16. Haile M, Ololo S, Megersa B. Willingness to join community-based health insurance among rural households of Debub Bench District, Bench Maji Zone, Southwest Ethiopia, BMC Public Health. 2014;14(1):1-10. https://doi. org/10.1186/1471-2458-14-591.

17. Wang H, Ramana G. Universal Health Coverage for Inclusive and Sustainable Development. 2014

18. Nyandekwe M, Nzayirambaho M, Kakoma JB. Universal health coverage in Rwanda: dream or reality. The Pan Afr Med J. 2014;17. https://doi.org/10.11 604/pamj.2014.17.232.3471.

19. Naseer M, Zahidie A, Shaikh BT. Determinants of patient's satisfaction with health care system in Pakistan: a critical review. Pakistan J Public Health. 2012:2(2):52

20. Devadasan N, Criel B, Van Damme W, Lefevre P, Manoharan S, Van der Stuyft P. Community health insurance schemes \& patient satisfactionevidence from India. Indian J Med Res. 2011;133(1):40.
21. Assefa F, Mosse A. Assessment of clients' satisfaction with health service deliveries at Jimma University specialized hospital. Ethiop J Health Sci. 2011; 21(2):101-10. https://doi.org/10.4314/ejhs.v21i2.69050.

22. Al-Abri R, Al-Balushi A. Patient satisfaction survey as a tool towards quality improvement. Oman Med J. 2014;29(1):3-7. https://doi.org/10.5001/omj.2 014.02 .

23. Mohammed S, Sambo MN, Dong H. Understanding client satisfaction with a health insurance scheme in Nigeria: factors and enrollees experiences. Health Res Policy Syst. 2011;9(1):1-8. https://doi.org/10.1186/1478-4505-9-20.

24. Kuzma J, Solomom J, Masono A, Manari B, Hopping J, Pasum E, et al. Assessment of patients' satisfaction with rural health services. Contemp PNG Stud. 2012;17:60-7.

25. Bekele A, Taye G, Mekonnen Y, Girma W, Degefu A, Mekonnen A, et al. Levels of outpatient satisfaction at selected health facilities in six regions of Ethiopia. Ethiop J Health Dev. 2008;22(1):42-8. https://doi.org/10.4314/ejhd. v22i1.10061.

26. Dalinjong PA, Laar AS. The national health insurance scheme: perceptions and experiences of health care providers and clients in two districts of Ghana. Heal Econ Rev. 2012;2(1):1-13.

27. Badacho AS, Tushune K, Ejigu Y, Berheto TM. Household satisfaction with a community-based health insurance scheme in Ethiopia. BMC Res Notes. 2016:9(1):1-10. https://doi.org/10.1186/s13104-016-2226-9.

28. Mitiku Kebede K, Geberetsadik SM. Household satisfaction with communitybased health insurance scheme and associated factors in piloted Sheko district; Southwest Ethiopia. PLoS One. 2019;14(5):e0216411. https://doi. org/10.1371/journal.pone.0216411.

29. Sagaro GG, Yalew AW, Koyira MM. Patients' satisfaction and associated factors among outpatient Department at Wolaita Sodo University Teaching Hospital, Southern Ethiopia: a cross sectional study. Sci J Clin Med. 2015;4(5): 109-16. https://doi.org/10.11648/j.sjcm.20150405.16.

30. CSA I. Ethiopia demographic and health survey 2011. Addis Ababa and Calverton: Central Statistical Agency and ICF International; 2012. p. 430.

31. Robyn PJ, Bärnighausen T, Souares A, Savadogo G, Bicaba B, Sié A, et al. Does enrollment status in community-based insurance lead to poorer quality of care? Evidence from Burkina Faso. Int J Equity Health. 2013;12(1): 1-13. https://doi.org/10.1186/1475-9276-12-31.

32. Boateng $D$, Awunyor-Vitor D. Health insurance in Ghana: evaluation of policy holders' perceptions and factors influencing policy renewal in the Volta region. Int J Equity Health. 2013;12(1):1-10. https://doi.org/10.1186/14 75-9276-12-50.

33. Mebratie AD, Sparrow R, Yilma Z, Alemu G, Bedi AS. Dropping out of Ethiopia's community-based health insurance scheme. Health Policy Plan. 2015;30(10):1296-306. https://doi.org/10.1093/heapol/czu142.

34. Aggrey M, Appiah SCY. The influence of clients' perceived quality on health care utilizat. 2014

35. Savitha B. A qualitative analysis of declining membership in micro health insurance in Karnataka. SIES J Man. 2014;10(1):12-21.

36. Wulifan JK, Bagah DA, Agyei-Baffour P. Assessing factors that influence sustainability of the National Health Insurance in Ghana: A study of Nadowli District scheme in Northern Ghana. Int J Innov Res Dev. 2014;3(9):142-57.

\section{Publisher's Note}

Springer Nature remains neutral with regard to jurisdictional claims in published maps and institutional affiliations.

Ready to submit your research? Choose BMC and benefit from:

- fast, convenient online submission

- thorough peer review by experienced researchers in your field

- rapid publication on acceptance

- support for research data, including large and complex data types

- gold Open Access which fosters wider collaboration and increased citations

- maximum visibility for your research: over $100 \mathrm{M}$ website views per year

At $\mathrm{BMC}$, research is always in progress.

Learn more biomedcentral.com/submission 